\title{
LA RELACIÓN PSICONEURAL EN EL ESTRÉS O DE LAS NEURONAS A LA COGNICIÓN SOCIAL: UNA REVISIÓN EMPÍRICA
}

Manuel Campos Roldán ${ }^{1}$

(Recibido el 02/04/2007, aceptado el 09/05/2007)

\section{RESUMEN}

El trabajo revisa los mecanismos neurales que hacen posible la relación entre actividad cerebral, percepción-evaluación de acontecimientos y contexto social en el desenlace del estrés. Sostiene la tesis de que dicha secuencia cristaliza la relación psiconeural y de que ésta reside en las conexiones entre el córtex prefrontal y el circuito núcleo talámico dorsomedialamígdala.

Palabras clave: Relación Psiconeural, Percepción, Estrés, Corteza Prefrontal, Núcleos Talámicos, Amígdala.

\begin{abstract}
It reviews the brain activity, facts perception-appraisal, social context and neural mechanisms related in stress processes. In this paper, that sequence defines the psychoneural relation, situated in the prefrontal cortex and thalamus dorsomedial-amygdala circuit.
\end{abstract}

Keywords: Psychoneural relation, Perception, Stress, Prefrontal cortex, Thalamic nucleus, Amygdala.

\section{INTRODUCCIÓN}

El problema de la relación psiconeural es legado por uno de los problemas principales de la historia de la filosofía, pero, desde el punto de vista de la ciencia psicológica, se le puede plantear como problema de la relación entre condiciones sociales de existencia, subsistemas cerebrales y cognición social. A este último sí puede dársele una respuesta precisa. El marco conceptual de la investigación realizada es la teoría e investigación en psicología y neurobiología de las emociones, en especial del estrés.

\footnotetext{
1 Docente de la Facultad de Psicología, Universidad Nacional Mayor de San Marcos.
} 


\section{El concepto de estrés}

El estrés es producto del conflicto, término que proviene del latín conflictus, raíz que alude al instante más intenso, violento y difícil de resistir en un combate, a tal punto que parece incierto el resultado final de la pelea. El concepto implica contraposición de fuerzas. Puesto que en tal condición se percibe que la supervivencia o el bienestar están en riesgo de ser dañados, el resultado es estrés o tensión.

Tensión es el estado emocional de ansiedad, inquietud y agitación derivado de la concurrencia de fuerzas contrarias. Su sinónimo es estrés, un estado de tensión producto de la percepción y evaluación de un acontecimiento repentino, momentáneo o prolongado como nocivo para el bienestar del organismo o la persona.

Ajuste es equilibrio, integración de mecanismos de autorregulación aptos para el afrontamiento de condiciones productoras de estrés o tensión. Es enteramente incorrecto asociar ajuste a adecuación. Así se obviaría que adaptación implica ganancia de aptitud, mientras adecuación sugiere igualación al contexto, mimetismo. A la vez, las reacciones infructuosas al estrés devienen desórdenes emocionales analizables como desajustes de la personalidad.

Los desajustes de la personalidad como consecuencia de la tensión comenzarían desde el lenguaje. El lenguaje es una dimensión de la conducta. No sólo es mediador de las relaciones sociales, sino regulador de la autorreferencia y del lenguaje interiorizado. En este plano se puede constatar la relación pensamiento-lenguaje: las dificultades se enfrentan primero en términos lingüísticos encubiertos o interiorizados: se pregunta qué hacer, si se podrá afrontar la dificultad, si se saldrá bien librado de ella, etc.

Por su parte, stress (españolizado como "estrés") viene de strictus, participio del verbo latino stringere, y cuya acepción es "provocar tensión". La historia del concepto suele retrotraerse al físico y biólogo inglés Robert Hooke (1635-1703), que lo usó en su indicación a los ingenieros sobre los riesgos que acarrea la construcción de estructuras que no sean capaces de resistir fenómenos naturales. ${ }^{1}$ En ciencias de la salud, el vocablo fue propuesto por el médico austrohúngaro Hans Selye (1907-1982) en 1949, quien lo afinó para la Organización Mundial de la Salud (OMS) como "respuesta no específica del organismo a cualquier demanda del exterior". ${ }^{2}$ Pero la inspiración es de Claude Bernard (1813-1878), quien escribió que: "las influencias exteriores no producen modificaciones y perturbaciones en la intensidad de las funciones del organismo, sino en tanto que el sistema protector del medio orgánico resulta insuficiente en condiciones dadas". ${ }^{3}$

\section{La teoría de las emociones de William James y sus críticos}

Selye propuso el nombre; no descubrió el síndrome. ${ }^{4}$ Fue atinada su afirmación de que lo que él pretendió fue "trazar conexiones fijas entre lo conocido anteriormente y lo desconocido hasta entonces" 5 .

Pertenece al conocimiento anterior, aludido por Selye, la teoría de la movilización de la energía formulada por el fisiólogo estadounidense Walter B. Cannon (1871-1945) en 1915. En ésta se describe el desenlace de la emoción como un proceso de despliegue de energías al enfrentarse situaciones de tensión como miedo, enojo o furia. 
En 1927, Cannon rebatió la teoría de la emoción de William James (1842-1910), quien sostuviera que la sensación de los cambios corporales que se producen a raíz de la percepción de un acontecimiento amenazante es la emoción. ${ }^{6}$ Antes de Cannon, en 1900 el fisiólogo inglés Charles Scott Sherrington (1857-1952), Premio Nobel 1932, había refutado la tesis de James seccionando médulas espinales de perros a nivel del cuello, separando de ese modo las conexiones entre el cerebro y los nervios que conducen información de la periferia del cuerpo y de los órganos viscerales. Sólo quedaron intocadas las vías que conducen sensibilidad facial, de cabeza y cuello. No obstante ello, los perros expresaron con igual intensidad sus reacciones emocionales.

Las observaciones de Sherrington pondrían en entredicho la teoría de James, ya que el aislamiento del cerebro de la información proveniente del resto del organismo no tuvo efecto alguno sobre la conducta emocional. He aquí una de las premisas de Cannon en su controversia con la teoría jamesiana. La movilización de la energía en la respuesta emocional es la determinante de la reacción de emergencia, de alerta o luchar-huir, cuya ejecución demandaría una redistribución del torrente sanguíneo hacia la musculatura esquelética.

En apoyo de la polémica de Cannon acudirían las investigaciones de un alumno suyo, el psicólogo californiano Philip Bard (1898-1977). Él removió regiones cerebrales en gatos empezando por la corteza sin lograr signo alguno de eliminación de reacciones emocionales; recién al extirpar la porción caudal del hipotálamo se vio que desaparecían las reacciones de ira. Bard publicó estos primeros estudios suyos en 1928. En 1932, el neuroanatomista estadounidense Stephen W. Ranson (1880-1942) ingresó al hipotálamo con métodos estereotáxicos (con éstos se coloca con precisión electrodos en estructuras encefálicas profundas) estimulando diversos núcleos en animales anestesiados. Logró provocar reacciones fisiológicas controladas por el sistema nervioso autónomo (SNA), como alteraciones de ritmo cardiaco, de presión arterial y motilidad gastrointestinal, contracción vesical y piloerección.

Quedaba así reafirmada la mediación del hipotálamo en el desarrollo y expresión de las reacciones emocionales. Extirpado o separado aquél, éstas aparecían parcialmente o disociadas: el animal se encrespaba, gruñía, emitía bufidos, retraía las orejas, mordía y manifestaba las reacciones fisiológicas ya mencionadas bajo control del SNA. Pero eran reacciones incoordinadas, al revés de lo que ocurría con el hipotálamo intacto. Además, ocurrían en ausencia de la corteza cerebral, que fuera removida en los trabajos de Bard. Del conocimiento de las conexiones hipotálamo-corteza cerebral se colegiría que a nivel de esta última tendría lugar la "lectura" de una situación como peligrosa. Las reacciones emocionales en animales decorticados configuraban así un cuadro de "falsa rabia".

\section{El proceso de estrés según Selye}

A su turno, en 1936, Selye, sometiendo a ratas albinas de laboratorio a estímulos diversos, ya sea administrándoles hormonas ováricas o de placenta o estímulos nocivos, como aplicación de venenos, exposición a frío y calor, notó una triple sintomatología: a) crecimiento de la corteza de las glándulas suprarrenales; b) reducción de linfocitos; y c) úlceras de estómago y duodeno.

Selye agrupó estos síntomas bajo el nombre de reacciones de alarma, por cuanto en ellas el organismo de los animales de investigación respondía de manera que parecía movilizarse 
en defensa de su existencia: inflamación de locus de infección, corticoides secretados en la sangre atacaban los agentes invasores, la médula suprarrenal segregaba adrenalina dirigiéndola a los músculos y dando eficiencia a los movimientos, acelerando respiración, aumentando ritmo cardiaco, etc.

Es decir, ésta era una etapa de adaptación al estímulo productor del estrés, el estresor: al comienzo, la respuesta estaba por debajo del nivel normal, pero luego superaba este nivel.

En la siguiente fase, se apuntalaba la concentración de corticoides, aunque sobre la concentración habitual, movilizándose únicamente el área perjudicada del organismo. Los demás procesos fisiológicos recuperaban su nivel normal de funcionamiento. Ésa es la etapa de resistencia, donde la exigencia de adaptación se incrementaba.

Cuando la defensa frente al estresor resultaba insuficiente, la fase de resistencia cedía a una tercera y última que era la etapa de agotamiento o fatiga. Entonces, las reacciones de alarma se reinstalaban (ver figura 1).

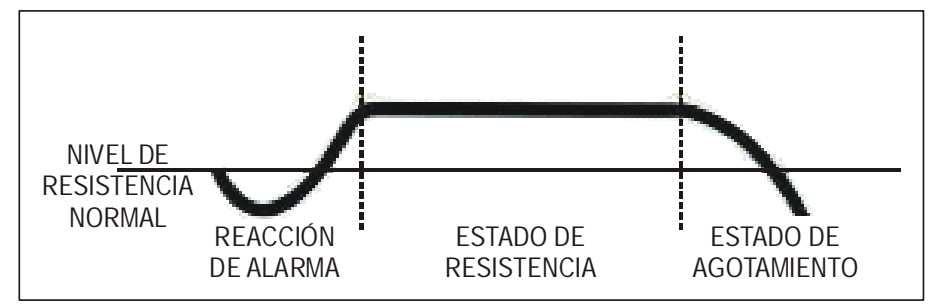

Fig. 1. Etapas del estrés según Selye.

Las tres etapas configuran lo que Selye llamó "síndrome general de adaptación". En uno de sus libros, Honorio Delgado (1892-1969) habló de uno de "los representantes más prominentes de la medicina psicosomática norteamericana, cuyas teorías se relacionan con la moda introducida por Selye del encarecimiento del stress, pero reveladoras de un criterio metodológico plausible", 7 refiriéndose así al psiquiatra estadounidense Harold G. Wolff (1898-1962). Para Wolff, los fracasos son causa de enfermedades. ${ }^{8}$ Thomas H. Holmes $(\dagger 1988)$, psiquiatra influido por Wolff y el neuropsiquiatra suizo-estadounidense Adolf Meyer (1866-1950), sostuvo una suerte de teoría sociogenética del estrés al insistir en que éste era resultado de las fluctuaciones generales en las condiciones de existencia.

Holmes y otro colega suyo, Richard Rahe (1936), confeccionaron en 1967 una escala de unidades que puntúa los efectos emocionales que producen en las personas los cambios drásticos en su vida (Life-Changes Units Scale). Renovada por Rahe en 2001, ${ }^{9}$ en ella se listan situaciones como muerte del cónyuge, divorcio, matrimonio, cambios de domicilio, entre otras, como circunstancias generadoras de estrés.

A fin de cuentas, el argumento inaugural de Bernard respecto de la indisociable relación entre el contexto y la resistencia fisiológica, podría decirse, estaría largamente convalidado. Además, James no habría estado del todo errado respecto del mecanismo periférico de las emociones, así como tampoco al anticipar el mecanismo central que las desencadena: la relación percepción-evaluación. 


\section{Planteamiento del problema}

El problema que faltaría responder es el de los mecanismos neurales que hacen posible la relación entre actividad cerebral, percepción-evaluación y contexto social. Es a partir de la secuencia percepción-evaluación, prevista por James, que se desencadena el estrés. La tesis que se sostiene en esta revisión empírica es que dicha secuencia define la relación psiconeural, y ésta se decide en la estructura del córtex prefrontal en su relación con el circuito núcleo talámico dorsomedial-amígdala. Es decir, lo incluido en el prefijo "psico" concierne a la actividad prefrontal como primera etapa del proceso en cuestión.

\section{MÉTODO}

El método seguido para responder el problema fue el análisis de las vías neurales involucradas en la transmisión de información visceral y sensorial y en las conexiones tálamo-amígdalacorteza prefrontal que median el proceso de percepción-evaluación de sucesos durante el desenlace del estrés.

\section{Relaciones recíprocas entre núcleo talámico dorso medial, amígdala y corteza prefrontal}

Vista la intervención del hipotálamo en el desarrollo y expresión de reacciones emocionales, vía la manifestación de reacciones fisiológicas bajo control del SNA, hay que examinar cómo llega la información al córtex prefrontal, donde ocurrirá la "lectura" o interpretación de un suceso. Partamos del núcleo solitario, ${ }^{10}$ un grupo adrenérgico y noradrenérgico que rodea el fascículo solitario y recibe axones de los pares craneanos VII (nervio facial), IX (glosofaríngeo) y X (vago o neumogástrico). La porción caudal del núcleo solitario es el núcleo cardiorrespiratorio (véase figura 2).

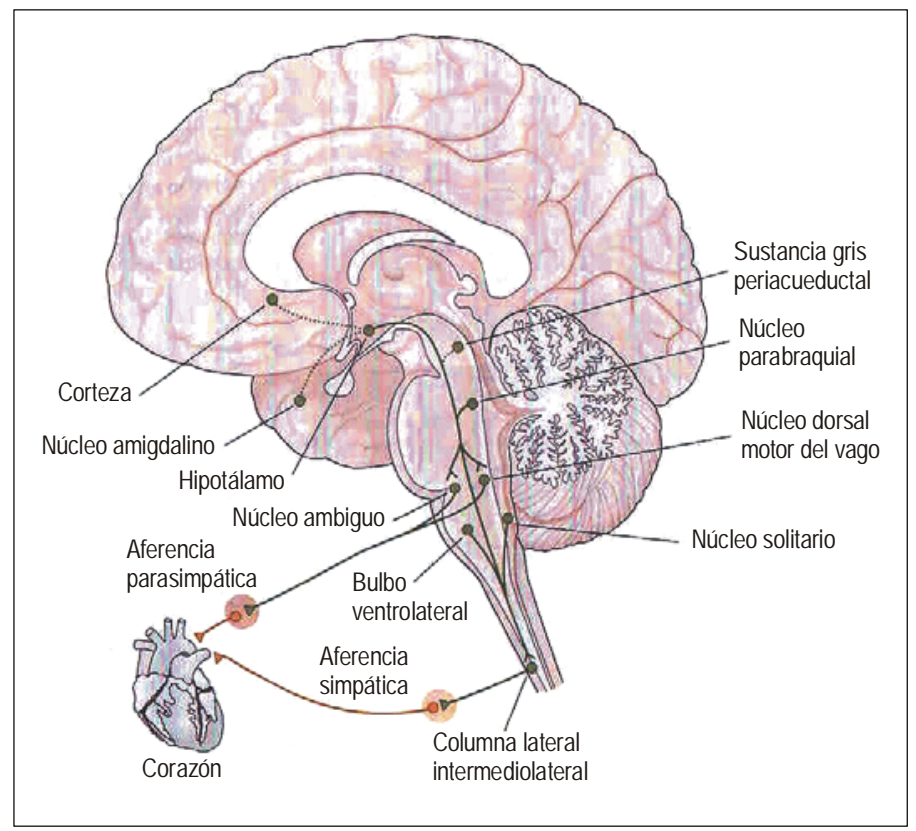

Fig. 2. Núcleo solitario y núcleo parabraquial. 
El núcleo cardiorrespiratorio controla la presión arterial, el ritmo respiratorio y la motilidad gastrointestinal. Sus proyecciones son: a) sectoriales; b) descendentes; y c) ascendentes. Estas últimas son pertinentes a la presente revisión.

A través del núcleo parabraquial, que como se ve en la figura 2 está en el dorso de la protuberancia, frente al punto de eferencia cerebelosa, el núcleo cardiorrespiratorio transmite información visceral a la sustancia gris periacueductal (SGP), ${ }^{11}$ al hipotálamo lateral y al núcleo central de la amígdala cerebral. Esta última es de singular interés para la presente revisión.

La amígdala es un conjunto de núcleos, también se la llama complejo nuclear amigdalino, y está casi dentro del lóbulo temporal. ${ }^{12}$ Consta de tres grupos de núcleos, núcleos basolaterales, núcleos centrales y núcleos corticomediales, y de dos eferencias: la estría terminal y la vía amigdalófuga ventral (véase figuras 3 y 4).

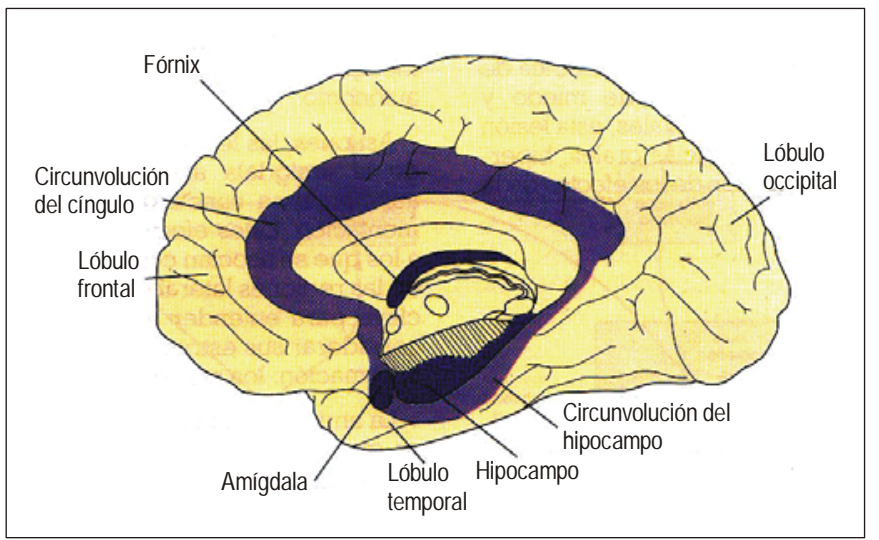

Fig. 3. Ubicación de la amígdala.

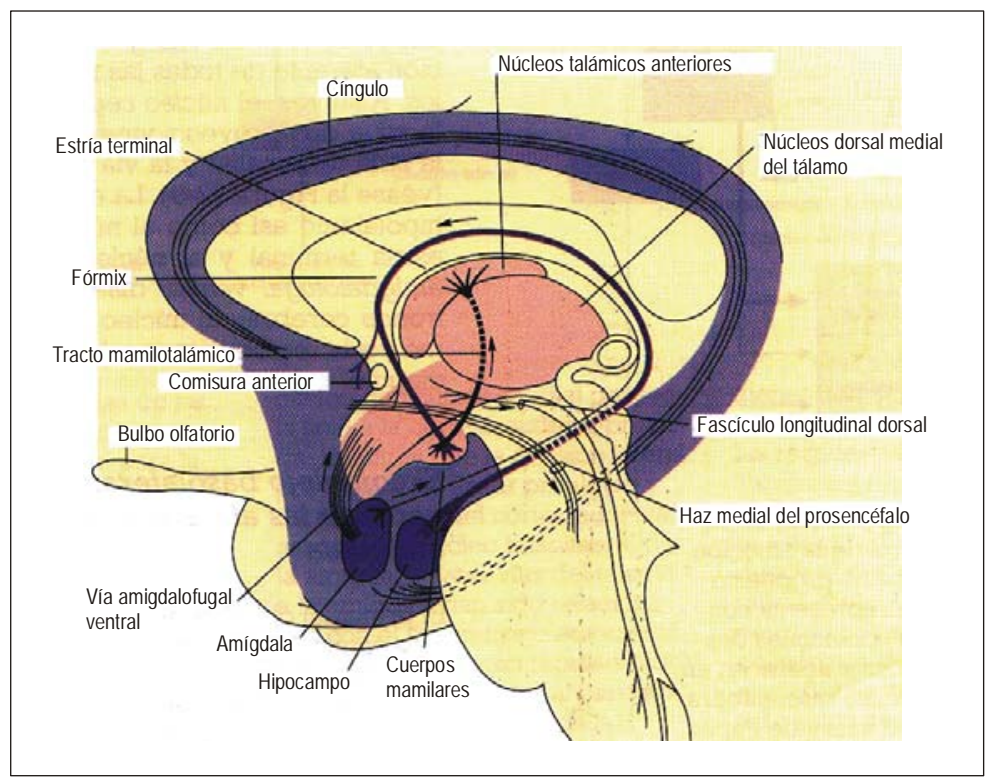

Fig. 4. Vía amigdalófuga ventral. 
Los núcleos basolaterales y los núcleos centrales se hallan en conexión recíproca con la neocorteza temporal, especialmente, con la corteza temporal inferior. Los núcleos centrales son un grupo celular dopaminérgico. A través de la estría terminal, se dirigen al núcleo hipotalámico paraventricular, el córtex orbitofrontal y la circunvolución del cíngulo. El primero regula la función hipofisaria, mientras la corteza orbitofrontal es una parte del córtex prefrontal que también provee fibras aferentes a la amígdala; tanto la corteza prefrontal como el cíngulo y la misma amígdala se incluyen en el córtex de asociación límbico.

A su turno, los núcleos corticomediales se conectan bilateralmente con las vías del sistema olfativo. Además de conectarse con el tronco cerebral, la vía amigdalófuga ventral transmite información al núcleo dorsomedial del tálamo y la porción delantera del cíngulo.

El tálamo consiste en dos masas esféricas de tejido gris situadas dentro de la zona central del cerebro, entre los dos hemisferios (ver figura 5).

Se distinguen en él cuatro superficies o caras: medial, lateral, superior e inferior y dos polos: anterior y posterior (ver figura 6).

Es un punto de integración funcional, pues, excluyendo vías olfatorias, todas las entradas sensoriales terminan en sus núcleos y de allí cursan hacia la corteza cerebral. Consta de dos grupos nucleares: a) núcleos de relevo; y b) núcleos de proyección difusa.

Los núcleos de relevo son vitales para las funciones cerebrales ${ }^{13}$. Desde niveles inferiores a la corteza cerebral transmiten a esta información apta para el movimiento, la percepción y cognición en general. Lo hacen enviando sus axones hacia áreas precisas de la corteza cerebral. Respecto de la toma de conciencia, el circuito involucrado es núcleo dorsomedialamígdala-córtex prefrontal.

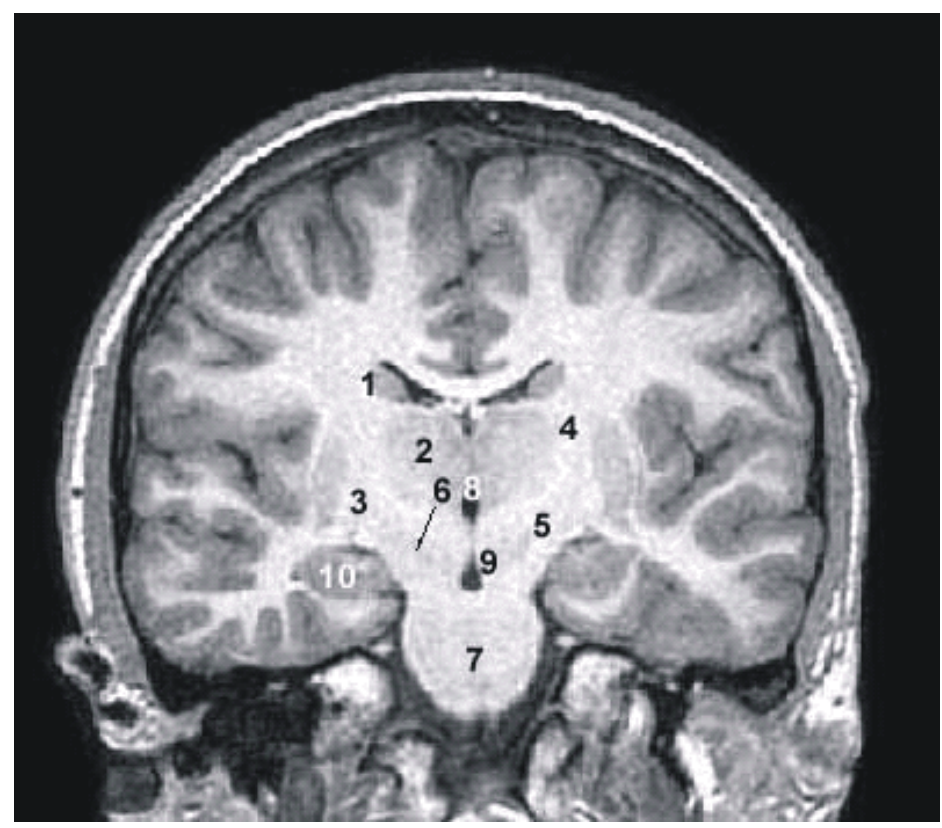

Fig. 5. Tálamo (en zona marcada con número 2). 
LA RELACIÓN PSICONEURAL EN EL ESTRÉS O DE LAS NEURONAS A LA COGNICIÓN SOCIAL: UNA REVISIÓN EMPÍRICA

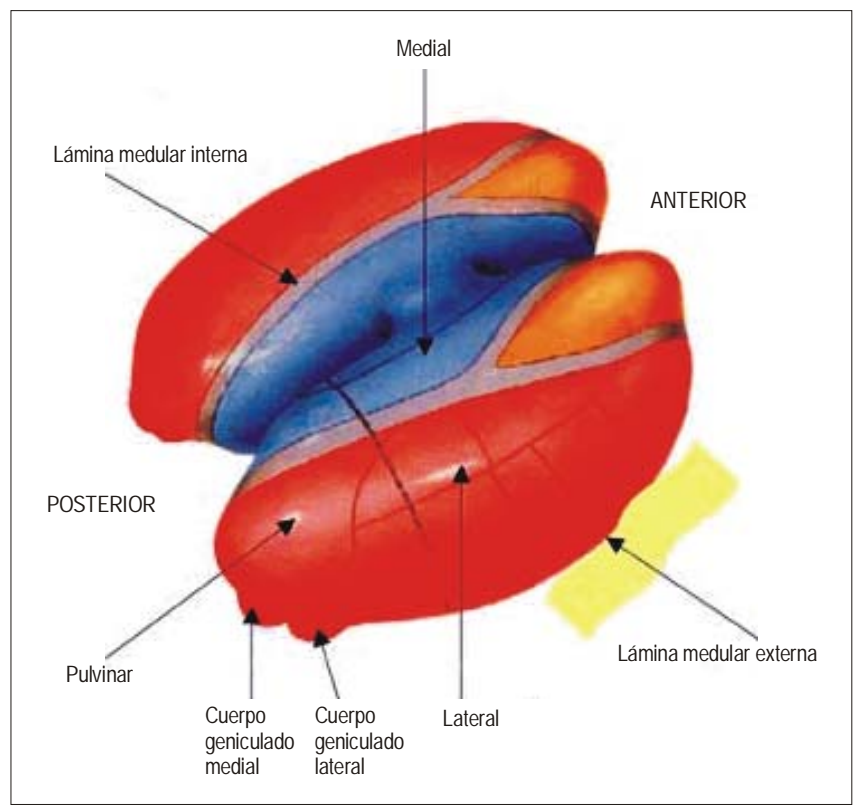

Fig. 6. Zonas del tálamo.

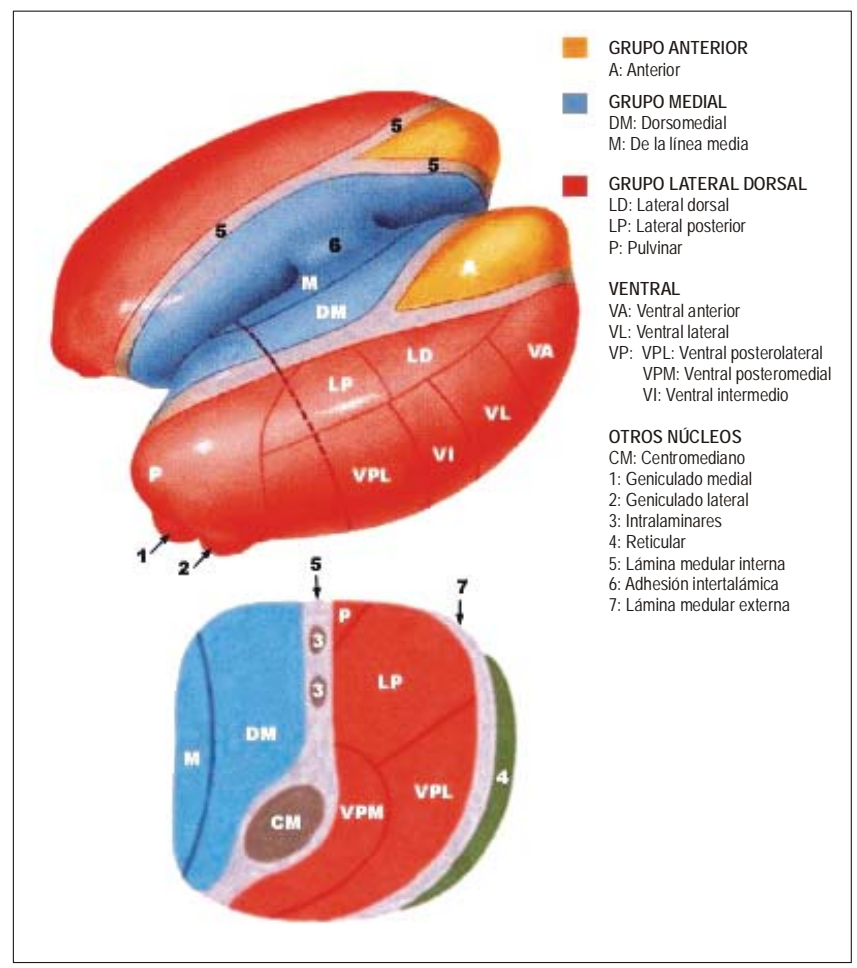

Fig. 7. Núcleos talámicos. 
Manuel Campos R

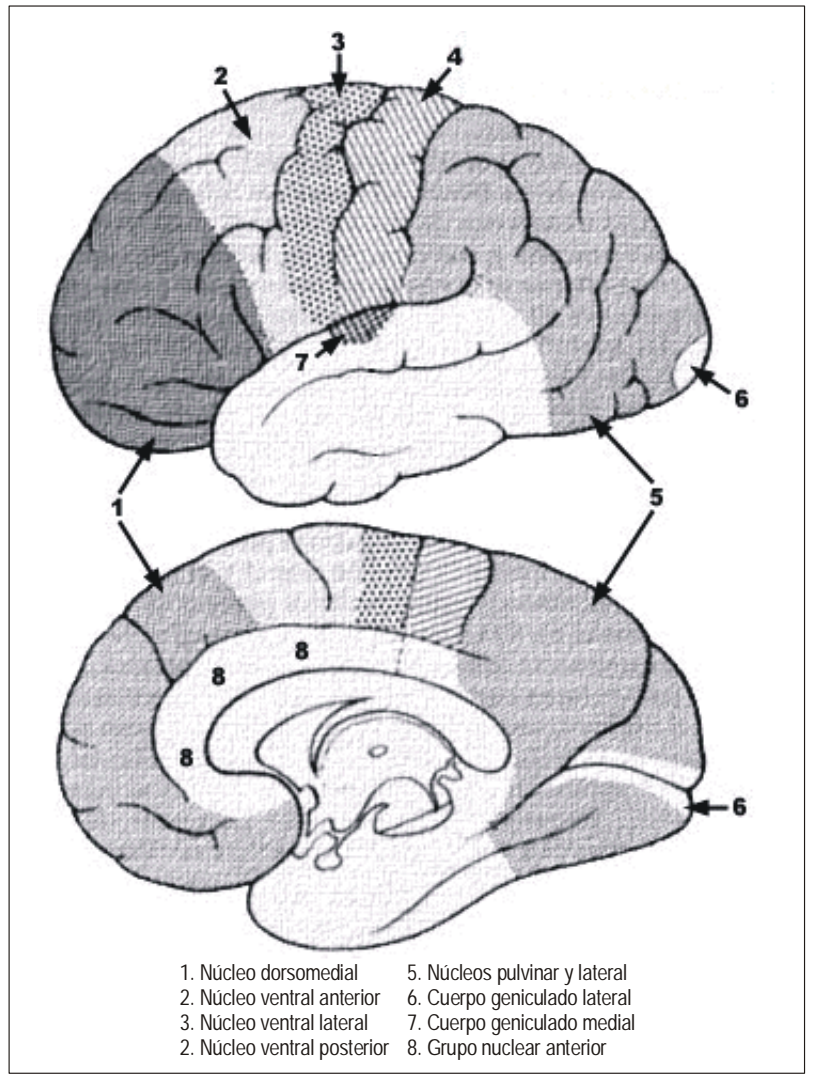

Fig. 8. Proyecciones tálamo-corticales.

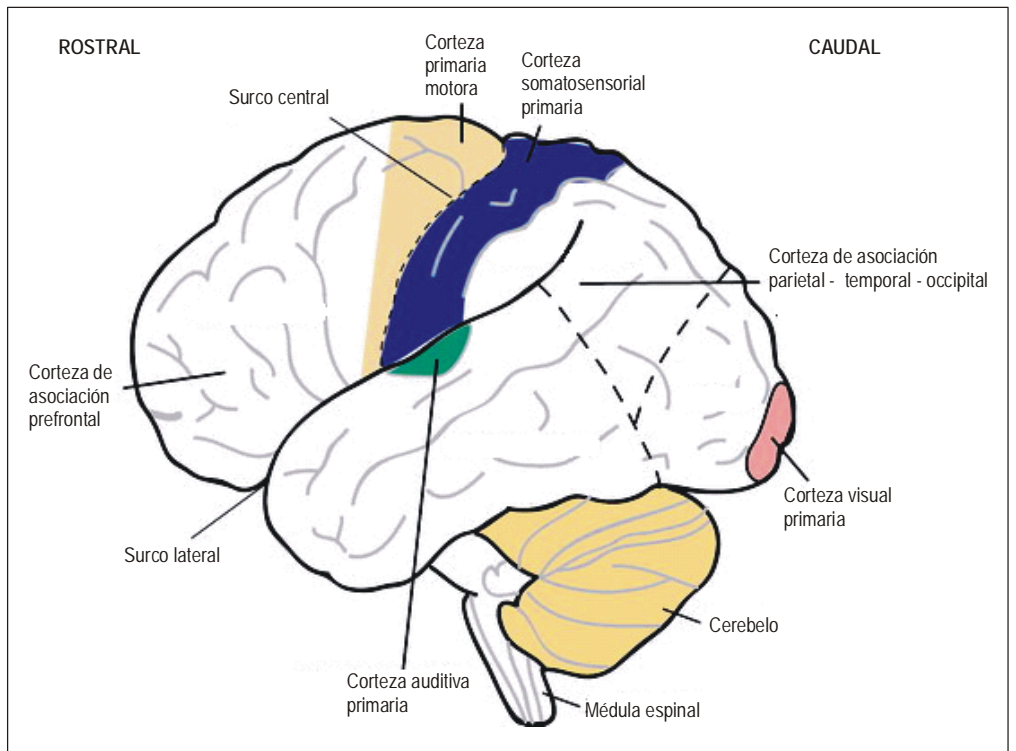

Fig. 9. Áreas funcionales de la corteza cerebral y corteza de asociación. 


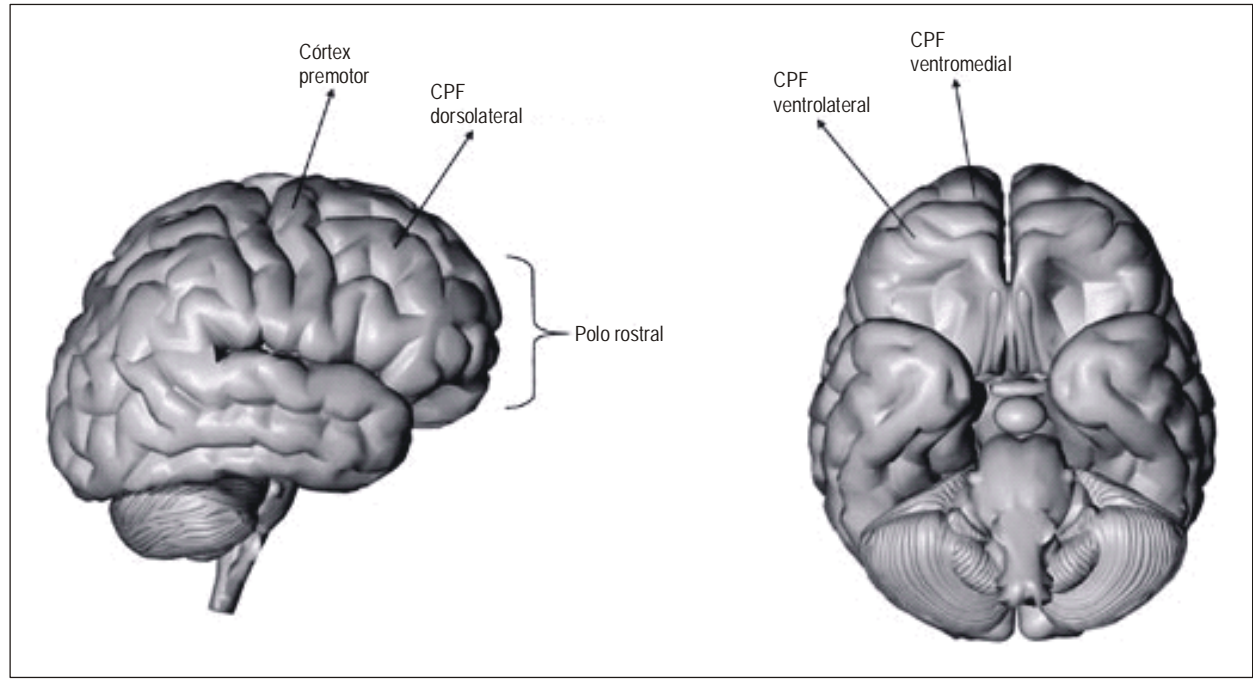

Fig. 10. Córtex prefrontal (CPF).

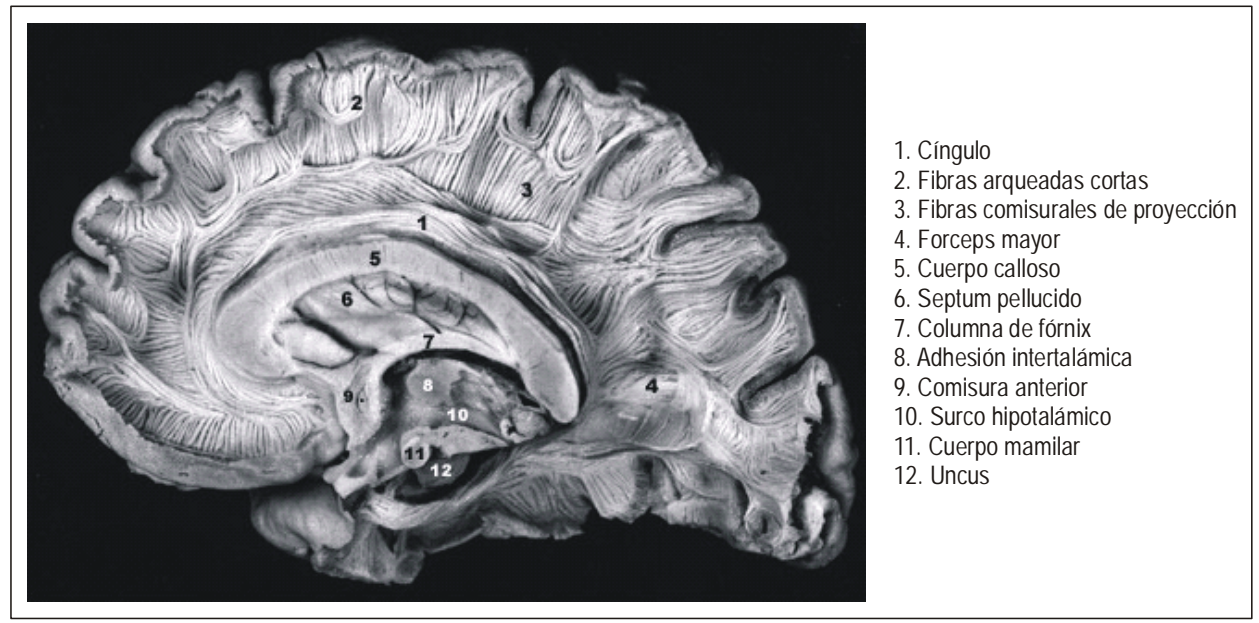

Fig. 11. Cíngulo.

El núcleo dorsomedial consta de dos grupos de células, uno de células grandes, las del núcleo dorsomedial magnocelular, y otro de células pequeñas, las del núcleo dorsomedial parvocelular. El núcleo dorsomedial magnocelular recibe fibras del grupo nuclear amigdalino y la corteza temporal inferior. El núcleo dorsomedial parvocelular se proyecta a toda la corteza prefrontal, al extremo de que las lesiones que se produzcan en ésta, al interrumpirse las conexiones, devendrán en degeneración celular en esta división dorsomedial.

Véase la figura 7 para detalle de los grupos nucleares y las conexiones talámicas. Los núcleos talámicos intralaminares (entre ellos, el más voluminoso y definido es el centromediano-CM-, con el que el núcleo dorsomedial tiene conexiones), ${ }^{14}$ en la figura 7 signados con el número 3 , son núcleos de proyección inespecífica, a diferencia de los que se proyectan a zonas puntuales de la corteza cerebral. Al revés de éstos, los núcleos 
intralaminares se proyectan a toda la corteza cerebral, "despertándola", jugando así un rol especial en el mantenimiento del estado de alerta y la atención selectiva.

La reciprocidad de la inervación entre núcleo talámico dorsomedial y amígdala se evidencia en el hecho de que las lesiones en ésta se siguen de degeneración tisular en el primero y viceversa.

En la figura 8, se ven las proyecciones tálamo-corticales: el núcleo dorsomedial se proyecta a la corteza prefrontal, que con la convexidad temporo-parieto-occipital y el córtex de asociación límbico forman la corteza asociativa (ver figura 9, en la cual no se nota el sistema límbico -amígdala, cíngulo, por ejemplo- porque está cubierto por el manto cortical)

En la figura 10 se ve en la corteza prefrontal un polo anterior o rostral, una parte dorsolateral (áreas 9, 10 y 46 de Brodmann), una parte ventromedial o medial (áreas 9 y 10) y una ventrolateral, orbital u orbitofrontal (áreas 11, 12 y 47).

Las neuronas del núcleo dorsomedial magnocelular se proyectan hacia la parte medial y orbital de la corteza prefrontal. Mientras las neuronas del núcleo dorsomedial parvocelular lo hacen hacia las áreas prefrontales laterales y dorsales.

Las conexiones entre núcleo talámico dorsomedial y corteza prefrontal aparecen recién en primates y seres humanos. Por tanto, son filogenéticamente recientes o tardías. E, histológicamente, configuran la estructura denominada corteza frontal granular, como se designa a las neuronas de las capas II y IV de la neocorteza. ${ }^{16}$

Cada parte de la corteza prefrontal forma en realidad un circuito. Así tenemos un circuito prefrontal dorsolateral (CPD), un circuito prefrontal medial (CPM) y un circuito orbitofrontal (CPO). El CPD se proyecta a la cabeza del núcleo caudado y de éste hacia el núcleo ventral anterior del tálamo y el núcleo dorsomedial, retornando hacia el córtex prefrontal. El CPM transmite a la amígdala y la corteza del cíngulo. La figura 11 puede darnos una idea del intrincado entramado interneuronal involucrado.

El CPO, además de enlazarse con la amígdala, la corteza del cíngulo y el núcleo dorsomedial, también se proyecta al núcleo caudado, pero a la parte ventromedial de éste. La vía que parte del núcleo caudado prosigue el trayecto del CPD y retorna a la corteza orbitofrontal. ${ }^{17}$

Además de recibir fibras del núcleo dorsomedial, y a través del núcleo ventral lateral del tálamo, la CPF dorsolateral recibe fibras del núcleo dentado del cerebelo, una instancia de proyección meramente cortical. ${ }^{18}$ Es elocuente la existencia de un sistema cerebelomesencéfalo-tálamo-córtex motor, o dento-rubro-tálamo-cortical, para ser más exacto, ${ }^{19}$ como feedback periférico sensorial para la realización del movimiento.

Desde 1895 se tendría conocimiento del sistema de feedback sensorial periférico para la función motora en los trabajos desarrollados por Frederick Walker Mott (1853-1926) y Sherrington. Mostraron cómo la desaferentación completa de una extremidad, esto es, la remoción de los nervios sensoriales de un miembro, produce o va seguida de parálisis parcial en dicha parte. Experimentando con monos encontraron que la ablación total de las raíces sensoriales impedía que los animales pudieran usar sus extremidades para caminar, trepar o asir objetos con la facilidad habitual.

Una observación concluyente se obtuvo cuando se dejaron intactos los nervios aferentes musculares y se seccionaron sólo los aferentes cutáneos, es decir, las neuronas cuyos 
axones transmiten sensibilidad epidérmica: en este caso la parálisis fue total. Así, dedujeron que "los impulsos aferentes -tanto de la piel como del músculo, sobre todo los primeros-, en relación con la palma de la mano o con la planta del pie, son necesarios para la ejecución de los movimientos del más alto nivel" ${ }^{20}$

En la figura 12 se representan las conexiones cerebelo-tálamo-corticales.

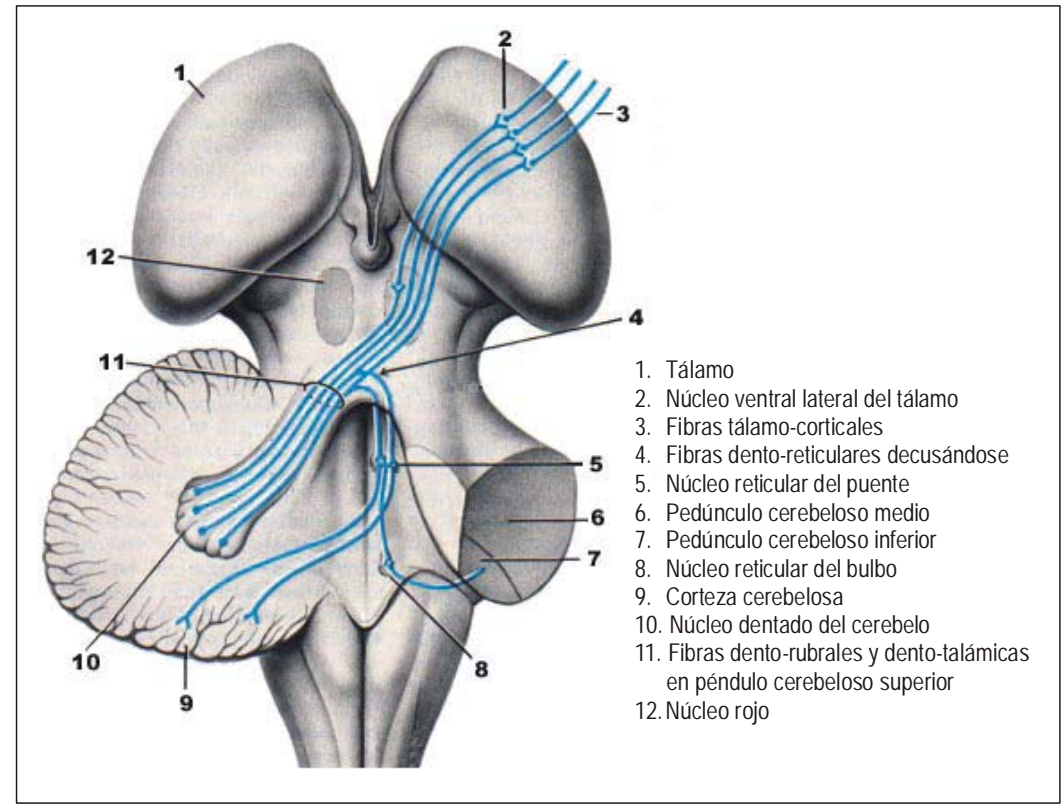

Fig. 12. Conexiones cerebelo-tálamo-corticales.

Hasta aquí se ha pasado revista a las vías propiamente relacionadas con el núcleo dorsomedial del tálamo, la amígdala y la corteza prefrontal con respecto a los procesos cognitivos de evaluación en el desenlace del estrés. Veamos los aspectos funcionales antes de proceder a una discusión final.

\section{RESULTADOS}

Nos referiremos en esta sección a dos resultados puntuales de la investigación neurocientífica que servirían de fundamento para deducir de ellos el papel que juegan la conexión núcleo dorsomedial talámico-amígdala-corteza prefrontal en los procesos de evaluación que redundan en la experiencia del estrés. Uno procede de los estudios sobre la relación flujo sanguíneofunción cerebral. El segundo concierne a las diferencias de velocidad en la transmisión neural tálamo-amígdala y corteza-amígdala.

\section{Flujo sanguíneo y actividad prefrontal}

El conocimiento de que el flujo sanguíneo es una función del metabolismo y de la actividad de los tejidos del organismo sustenta la elección del método de medición respectivo. La energía que despliega el trabajo fisiológico proviene en su mayor parte del desdoblamiento del trifosfato de adenosina (ATP), una molécula que contiene tres grupos fosfato, adenina y 
azúcar $^{21}$. Desdoblado el ATP, se descompondrá en difosfato de adenosina (ADP) y fosfato inorgánico. Pero puede reconstituirse desde sus restos por medio de una reacción que requiere de oxígeno y glucosa.

La actividad tisular supone así un incremento en la demanda de oxígeno. Por fin, como se preserva una proporción constante entre el número de fragmentos regenerados y las moléculas de oxígeno utilizadas en el proceso de recomposición, la actividad de un tejido cualquiera termina dependiendo del consumo de oxígeno. El oxígeno es facilitado al organismo por el torrente sanguíneo, exactamente por la hemoglobina que lo conduce desde las vías respiratorias; y un incremento en su demanda, por tanto, será cubierto por un flujo más elevado de sangre oxigenada u oxihemoglobina.

A fines de la década de 1970, un grupo de fisiólogos daneses liderado por Niels A. Lassen, ${ }^{22}$ usando un isótopo radiactivo del xenón, ${ }^{23}$ el xenón 133, disuelto en suero fisiológico estéril e inyectado en una de las arterias carótidas internas, investigaron con quinientos pacientes cuyos síntomas neurológicos transitorios (migraña o epilepsia, por ejemplo) se hallaban en estado de remisión. Más aún, no había signos debidos a lesión o anormalidad cerebral palmaria, lo cual se probó con pruebas electroencefalográficas, por ejemplo. En tales condiciones, les practicaron a aquéllos una arteriografía cerebral obteniéndose una radiografía de los vasos sanguíneos y, por ende, una visualización de la concentración del flujo sanguíneo encefálico. ${ }^{24}$

Las observaciones de Lassen y su equipo revelaron un patrón estándar del flujo sanguíneo en el cerebro en reposo muy específico y reproducible. Estando los sujetos de investigación despiertos, en posición horizontal, vale decir, en estado de reposo, los ojos cerrados, el laboratorio en silencio, sin recibir instrucción alguna ni ser acomodados por nadie, la imagen que se destacaba del trayecto sanguíneo no se mostró uniforme en toda la extensión de la corteza cerebral. Más bien, se vio más aglutinado en el área prefrontal del córtex cerebral, comparado con el flujo en las áreas prerrolándica y parieto-occipital. Incluso el aporte sanguíneo en algunas zonas del lóbulo temporal era menor.

Más exactamente, si el flujo medio es de $50 \mathrm{ml}$ por 100 gr de tejido cerebral y por minuto, el de la parte frontal en aquellas condiciones sería un 20-30\% superior a ese promedio. Y así, puesto que la densidad de capilares y neuronas en las distintas regiones corticales es similar, consiguientemente, la diferencia advertida en la intensidad de flujo sanguíneo registró que el nivel de actividad global del área frontal del cerebro en estado de reposo estaba en un 50\% más acrecentado que en las áreas dorsales.

Por tanto, de la relación funcional:

$$
\text { Flujo sanguíneo }=\mathrm{f}(\text { metabolismo }+ \text { actividad tisular })
$$

se deduce que el hallazgo de concentración de circulación sanguínea aumentada en las áreas prefrontales en estado consciente, pero en reposo, indica que éstas son las zonas corticales que en este estado seguirían "trabajando". Las diferencias de velocidad de transmisión neural tálamoamígdala y corteza-amígdala, justamente, fundamentarían la metáfora del "trabajo" cerebral.

\section{Transmisión entre tálamo-amígdala y corteza-amígdala}

Las imágenes obtenidas por tomografía de emisión de positrones (TEP) durante la ejecución de conductas verbales respaldan las observaciones de Lassen y sus colegas. En ellas puede observarse cómo se activan ciertas áreas vinculadas con el lenguaje. 
Como en el trabajo de Lassen, la TEP se basa sobre el principio fisiológico de la relación entre actividad funcional del cerebro, aporte sanguíneo y consumo de glucosa. La TEP procede infiltrando al torrente sanguíneo un análogo de la glucosa, la 2-desoxi-glucosa; las neuronas la retienen, la tratan como si fuera glucosa y le añaden un grupo fosfato. De aquí sale la 2-desoxi-glucosa-6-fosfato, que no se metaboliza, pero tampoco puede abandonar la zona en que se formó, pues su tamaño le impide cruzar la membrana neuronal.

Añadiéndose un isótopo radiactivo inocuo como el oxígeno, éste se integrará a las moléculas de 2-desoxi-glucosa-6-fosfato. Como al declinar a su forma no radiactiva, el oxígeno cobrará la propiedad de emitir positrones; éstos permitirán identificar la zona de metabolismo de glucosa y, consecuentemente, la zona cerebral en actividad. En la figura 13, por ejemplo, se ven las neuroimágenes cerebrales TEP durante el comportamiento verbal.

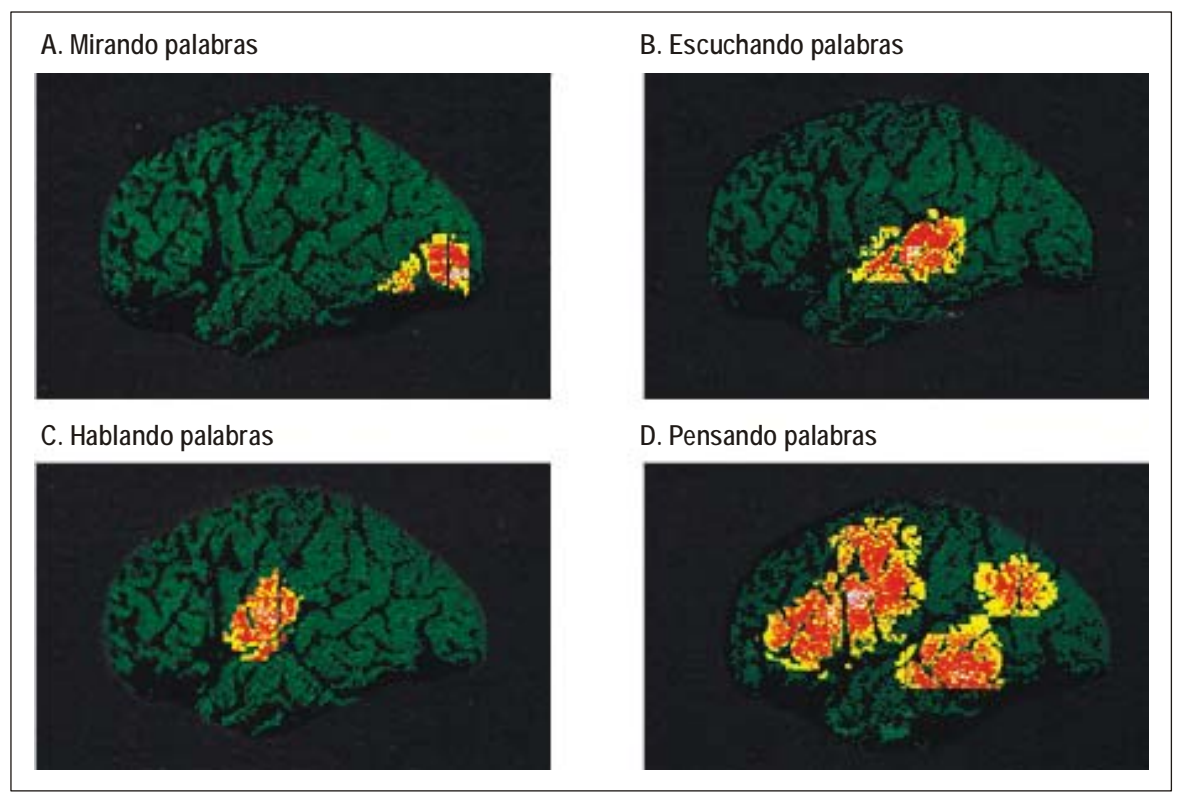

Fig. 13. Neuroimágenes TEP relacionadas con el lenguaje.

Es evidente que en (a), al leer o "mirar palabras", la corteza occipital está activa, mientras que, al oírlas (b), lo está el área de Wernicke. Igual ocurre cuando se "habla" (c), que es cuando entra en actividad el área de Broca. En cambio, al "pensar palabras", o simplemente al pensar (d), las imágenes parecen complicarse, pues es obvio el trabajo en el córtex prefrontal, aunque parece que éste recibe el soporte de las áreas visuales secundarias, de la convexidad temporo-parieto-occipital, del propio córtex motor y del área de Broca.

Como se señalara al comienzo, los desajustes de personalidad como resultado de la tensión comenzarían desde el lenguaje. Según esto, todo análisis situacional se haría en términos lingüísticos interiorizados, preguntándose la persona qué hacer, si se podrá afrontar una dificultad y si se saldrá bien librado. Los procesos de transmisión neural en tales circunstancias tendrían diferentes velocidades en lo atinente a las conexiones entre tálamo, amígdala y corteza. 
Joseph LeDoux ha hallado diferencias sugerentes en la velocidad de conducción entre los estímulos que llegan a la amígdala a través del tálamo y los que arriban a ella desde la corteza cerebral. Como él dice, el tálamo carece de la precisión de la corteza cerebral en la "interpretación" del estímulo, pero tarda menos cuando conduce hacia la amígdala. ${ }^{25}$

Experimentando con ratas de laboratorio, LeDoux observó que el estímulo que desde el tálamo llega directamente a la amígdala demora sólo 12 milisegundos, mientras que cuando lo hace desde la corteza hacia la amígdala demora prácticamente el doble. En términos breves, la ruta tálamo-amígdala es más veloz. Él califica al tálamo como un "procesador tosco y rápido", lo que implica que no puede "decirle al núcleo amigdalino exactamente qué está transmitiendo, pero puede suministrar señales más rápidas para avisar que podría haber algún peligro". ${ }^{26}$ Veamos en la sección final de esta revisión las consecuencias teóricas deducibles.

\section{DISCUSIÓN}

Un problema considerado por Donald Hebb como distintivo del comportamiento en los niveles más altos de la escala filogenética, que, de paso, compete a una psicología evolucionista, es la duración del lapso que discurre entre situación estímulo y respuesta. Mientras más se asciende en la escala evolutiva, mayor es la duración de dicho espacio de tiempo. El intervalo de esta brecha temporal sancionaría, para Hebb, la ocurrencia de procesos mediadores. Él definió proceso mediador como "una actividad del cerebro que puede retener la excitación producida por un acontecimiento sensorial después que éste ha cesado, permitiendo así que el estímulo ejerza su efecto algún tiempo después". ${ }^{27}$

Podría concluirse que descripciones como la concentración del flujo sanguíneo en el córtex prefrontal reseñada por Lassen y la dilación del arribo del impulso desde la corteza hasta la amígdala expuesta por LeDoux confirman "procesos mediadores" como los propuestos por Hebb. Pero, para efectos de una descripción e intelección psicológica de lo que sucede en experiencias como la del estrés, el lenguaje neurocientífico no sabe ir más allá de una exposición como la realizada en esta revisión. Y cuando lo intenta le es necesario trascender su propia terminología, su "know-how". ${ }^{28}$

Así, para Lassen y colegas: "La existencia de un flujo frontal intenso sugiere... que en estado de vigilia y reposo el cerebro trabaja en la planificación y selección de diferentes normas de comportamiento". ${ }^{29}$ LeDoux, por su parte, sitúa al lector en el caso de que, paseando por un bosque, oiga un ruido cercano: el sonido viajará rectamente a la amígdala por vía talámica; y también enfilará a ella desde el tálamo, pero cruzando por el córtex (recuérdese los circuitos prefrontales). La corteza "reconoce el sonido como el crujido de una rama que se rompe al pisarla, o como el sonido de una serpiente cascabel que mueve la cola. Para cuando la corteza lo ha averiguado, el núcleo amigdalino ya está empezando a defenderse contra la serpiente". ${ }^{30}$

A la corteza prefrontal se le asigna la responsabilidad de las funciones ejecutivas que regularían el accionar. ${ }^{31}$ Funciones ejecutivas son procesos cognitivos y habilidades conductuales reveladas en el esclarecimiento de objetivos y la planificación de acciones conducentes a la consecución de esos objetivos. El concepto de función ejecutiva estuvo in nuce en Alexander R. Luria (1902-1977), cuando, además de reconocer en los lóbulos frontales una intervención en la activación, señaló que éstos regularizan "las acciones y 
movimientos voluntarios y... la programación de las formas más altamente organizadas de la actividad humana". 32

En la cuarta (y última) edición del año 2000 de Principles of Neural Science, el Premio Nobel Eric R. Kandel escribía: "Hasta el momento no sabemos cómo la activación de neuronas específicas da origen a la percepción consciente ni siquiera en el caso más sencillo". ${ }^{33}$ Pero ocurre que esa percepción consciente es el advenimiento de un nivel de realidad que emerge o trasciende -"no sabemos cómo"- del "diálogo" entre o al interior de los circuitos núcleo talámico dorsomedial-amígdala-corteza prefrontal. Esta disparidad fenoménica cerebro-subjetividad implica para el filósofo estadounidense Donald Davidson (1917-2003) un monismo anómalo (anomalous monism): ${ }^{34}$ los hechos psicológicos tienen sustrato neural, pero no todos ellos pueden describirse ni explicarse en términos físicos.

Cabe precisar que Davidson usa "anomalous" sujetándose a las raíces griegas, ${ }^{35}$ donde $a$ es privación y nomos es ley. ${ }^{36}$ De acuerdo con esto, el contenido vivencial de la experiencia subjetiva y la intencionalidad de los procesos cognitivos escapan a las leyes físico-químicas: nomológicamente, ${ }^{37}$ las ciencias sociales son irreductibles a las ciencias físicas. Pero esta disociación entre las regularidades de los fenómenos psicológicos y las de los fenómenos físicos justifica más al monismo emergentista, que afirma la unicidad de la realidad material, cuyos niveles ontológicos devienen evolutiva y cualitativamente novedosos. Y acredita también a la evaluación psicológica y la explicación psicosocial.

De modo que, como reza el subtítulo de la presente revisión, habría que transitar "de la neurona a la cognición social". El concepto cognición social designa el proceso de análisis, almacenamiento, interpretación y recuperación de información concerniente al contexto normativo y cultural dentro del cual interactuamos las personas. Es, en otras palabras, la representación personal y colectiva que se expresa en las creencias y valores adquiridos en el curso de la historia subjetiva e intersubjetiva.

Así entendido, el proceso de cognición social se constituye como un organizador y conductor de las acciones humanas. Consiguientemente, en el uso del concepto mente tendríamos que discernir y aislar dos sentidos, uno fenomenológico, que pertenecería al análisis filosófico, y otro organizador, que pertenecería a la psicología. ${ }^{38}$

Ambos sentidos los fusiona René Descartes (1596-1650), por lo que cabría decir que la psicología contemporánea recuperó la mente cartesiana. Para Descartes, mente es el sujeto del pensamiento, y éste es "todo cuanto acontece en nosotros de manera tal que de ello tengamos conciencia". Ello reúne "no sólo el comprender, el querer, el imaginar, sino también sentir es considerado aquí lo mismo que pensar". ${ }^{39}$

En sentido fenomenológico, "mente" es sinónimo de autoconciencia, pero como concepto referido a la organización de la conducta, la mente hace, produce o crea. Este segundo sentido se halla ya en Jean Piaget (1896-1980). Él citaba al psiquiatra francés Pierre Janet (1859-1947) cuando decía que los determinantes de la experiencia subjetiva están en la experiencia objetiva, en la relación interpersonal. En tal sentido, la memoria surgiría del esfuerzo por relatar; la creencia, de la confianza depositada en las promesas escuchadas desde la experiencia de la relación padre-hijo; y la reflexión o deliberación, de las experiencias o relaciones sociales de intercambio de ideas o de "polémica".

Esas experiencias obran, anota Piaget, "según aquella regla general que dice que uno acaba siempre por aplicarse a sí mismo las conductas adquiridas en función de los otros". ${ }^{40}$ En 
conclusión, reflexión es "discusión social interiorizada". ${ }^{41}$ Aquí se concreta el tránsito desde las conexiones neurales hacia las relaciones cognitivo-sociales.

\section{NOTAS}

1 Véase Lazarus y Lazarus, Pasión y razón, p. 280.

2 Citado en Ortega, 1999, Estrés y trabajo.

3 Bernard, Introducción al estudio de la medicina experimental, p. 197.

4 E incluso habría errado en la elección del término, algo explicable por su poco dominio del idioma inglés; Selye habría querido referirse al vocablo strain, que, en inglés, es el efecto del «estrés»; ver Fernández-Abascal, Fernández-Castro, Proceso de estrés, p. 424.

5 Citado en Troch, El stress y la personalidad, p. 15.

6 James, Principios de psicología, p. 915.

7 Delgado, Enjuiciamiento de la medicina psicosomática, p. 113.

8 Delgado, Ibíd.

9 Véase Fernández-Abascal, Fernández-Castro, ob. cit., pp. 428-429; Reeve, Motivación y emoción, y Petri y Govern, Motivación.

10 Debe tenerse presente que en neuroanatomía se llama núcleo no sólo al locus central del soma o cuerpo de una neurona, sino también a todo grupo o racimo de cuerpos neuronales 0 de células que teñidas tienen un aspecto uniforme.

11 La relación con la sustancia gris periacueductal es de peculiar interés, pues su estimulación eléctrica produce analgesia. En 1969, por ejemplo, se realizó cirugía abdominal en ratas albinas sin necesidad de inyectar anestésico alguno, sino estimulando solamente la SGP; ver Pinel, Biopsicología, p. 243.

12 Casi, por cuanto hay núcleos amigdalinos (como el central y el corticomedial, que luego veremos) que tienen una ubicación más bien extratemporal.

${ }^{13}$ El nombre de núcleos de relevo es meramente metafórico, pues no se trata de transmisión de mensajes electroquímicos en posta, pues en cada sinapsis la información es modificada y el código del mensaje ya no es el mismo. Y lo que hay que recordar siempre es que, si la relación entre núcleos talámicos y corteza cerebral es bilateral, el estado funcional de ésta influye en el modo como los núcleos talámicos filtran la información. Nauta sugiere que a los «núcleos de relevo» se los llame «estaciones de elaboración de datos». Véase Nauta y Feirtag, Organización del cerebro, pág. 61.

14 Por ello suele considerarse al núcleo dorsomedial como otro núcleo de proyección inespecífica.

15 Se ha cuestionado esta denominación por preservar una suerte de concepción asociacionista implícita en el sentido de mediación cortical entre funciones motoras y sensoriales. Ante ello, se propone el nombre de áreas corticales intrínsecas, las que, a diferencia de las que serían extrínsecas, no reciben información extratalámica; la propuesta es de Gerhard Werner en Mountcastle, Fisiología médica, vol. I, pág. 538.

16 Las células granulares tienen poco protoplasma pero un gran núcleo; son pequeñas, de unos $8 \mu \mathrm{m}$; su aspecto es poligonal y su ramificación dendrítica es cuantiosa, por lo que son exclusivamente receptoras, en especial de información procedente de áreas intracorticales. Su axón relativamente corto no sale de la corteza, e incide sobre neuronas próximas.

17 Se está dejando de lado deliberadamente otras estructuras subcorticales que, con el núcleo caudado, constituyen los ganglios basales (como el putamen, que con aquél conforman el neoestriado o estriado), y el globo pálido, puesto que, como se ha venido diciendo, la presente revisión se centra en las conexiones entre el núcleo dorsomedial del tálamo, la amígdala y la corteza prefrontal como circuito responsable de la cristalización de la relación psiconeural.

${ }^{18}$ El núcleo dentado pertenece al grupo de neuronas que forman el cerebro-cerebelo, es decir, aquellas fibras que se dirigen hacia la corteza cerebral, a diferencia de las que vienen de la médula espinal, que constituyen el sistema espinocerebeloso o de la rama vestibular del VIII par, que vienen a conformar el sistema vestibulocerebeloso. El núcleo ventral lateral tiene conexiones recíprocas con el área 6 de Brodmann, 0 área premotora.

${ }^{19}$ El nombre alterno de este sistema obedece al hecho de que, del núcleo dentado del cerebelo, las fibras pasan por el núcleo rojo parvocelular mesencefálico en su trayecto hacia el núcleo ventral lateral del tálamo.

20 Citados en Carpenter, Neuroanatomía humana, p. 263.

${ }^{21}$ La adenina es una de las cinco bases nitrogenadas que constituyen el ARN y el ADN.

22 Lassen es pionero de las técnicas de neuroimagen. Premio Novo Nordisk 1968, nacido en 1926, murió de cáncer en 1997.

${ }^{23}$ El xenón es un gas inerte 0 noble en el sentido de que no reacciona usualmente con otros compuestos.

${ }^{24}$ Véase Lassen y cols., Función cerebral y flujo sanguíneo. 
25 Ver LeDoux, El cerebro emocional, p. 181-182.

${ }^{26}$ LeDoux, ob. cit., p. 182.

27 Hebb, Psicología, pág. 83. Después de Hebb se ha considerado como proceso mediador toda actividad fisiológica, constructo o proceso psicológico, inexactamente, a nuestro juicio, pues él se refería a procesos postulados como propiamente cerebrales. No está de más recordar que una de las tesis epistemológicas (el empirismo lógico de Rudolf Carnap) concibe la ciencia como lenguaje que, a su vez, contiene un lenguaje observacional $\left(L_{0}\right)$ y un lenguaje teórico $\left(L_{t}\right)$. $L_{0}$ consta de términos descriptivos, mientras $L_{t}$, de palabras referidas a entidades concebidas como responsables de los fenómenos caracterizados por $\mathrm{L}_{0}, 0$ a procesos cognitivos, motivacionales 0 de aprendizaje deducibles como intermediarios entre $E$ y R. En el primer caso, se trata de constructos hipotéticos, mientras que en el segundo de variables intervinientes. Aquéllos y éstas son conceptos teóricos 0 de $L_{t}$.

${ }^{28}$ Ésta es una limitación propia del mismo ámbito o dimensión del análisis neurobiológico, y puede verse desde que en 1868 se documentara, por el médico John Harlow (1844-1907), el conocido caso de Phineas Gage (18231860). Harlow dijo que la barra de hierro que se incrustó en el cráneo de Gage atravesándole las áreas prefrontales dañó «el equilibrio entre sus facultades intelectuales y sus inclinaciones animales» (citado por Damasio, El error de Descartes, p. 27).

${ }^{29}$ Lassen y cols., Función cerebral y flujo sanguíneo, p. 198.

30 LeDoux, El cerebro emocional, p. 182.

31 Véase, por ejemplo, Kandel y otros, Principios de neurociencia, caps. 19 y 43.

32 Luria, Las funciones corticales superiores del hombre, p. 297.

33 Kandel y otros, ob. cit., p. 397.

34 Sobre el monismo anómalo, véase Davidson, Filosofía de la psicología, pp. 21-27.

35 Esta delimitación conceptual es insoslayable. «Anómalo» es una expresión cuya aceptación filosófica y psicológica en nuestro medio es problemática: como consta en el Diccionario RAE, aunque en una tercera acepción, «anomalía» significa, en biología, malformación.

${ }^{36}$ Ver Davidson's Anomalous Monism, en http://instruct.westvalley.edu/lafave/Donald_Davidson.html.

${ }^{37}$ Las leyes científicas son enunciados nomológicos en el sentido de enunciados legales 0 legaliformes, y constituyen «reconstrucciones conceptuales de las pautas del ser y del devenir», como las trata Bunge en Causalidad, p. 47.

38 Véase Chalmers, La mente consciente, pp. 34-48.

39 Véase Descartes, Los principios de la filosofía, I, 9, p. 26, nota 15.

40 Piaget, Seis estudios de psicología, pág. 67. Desde otra orilla, por así decir, el filósofo austro británico Ludwig Wittgenstein (1889-1951) diría que: «Un «proceso interno» necesita criterios externos»; ver sus Investigaciones filosóficas, § 580 , p. 363.

41 Piaget, Ibíd. Debe añadirse que la «reflexión» aquí referida es la misma que consigna el Diccionario como el acto de considerar algo nuevo y detenidamente.

\section{REFERENCIAS BIBLIOGRÁFICAS}

1. Bernard, C. (1865/1960). Introducción al estudio de la medicina experimental. México: UNAM.

2. Bunge, M. (1972). Causalidad. Buenos Aires: Eudeba.

3. Carpenter, M. (1978). Neuroanatomía humana. Buenos Aires: El Ateneo.

4. Chalmers, D. (1999). La mente consciente. Barcelona: Gedisa.

5. Damasio, A. (1996). El error de Descartes. Santiago de Chile: Andrés Bello.

6. Davidson, D. (1994). Filosofía de la psicología. Barcelona: Anthropos.

7. Delgado, H. (1960). Enjuiciamiento de la medicina psicosomática. Madrid: CientíficoMédica.

8. Descartes, R. (1644/1995). Los principios de la filosofía. Madrid: Alianza.

9. Fernández-Abascal, E. y Fernández-Castro, J. (2002). Proceso de estrés. En Francesc Palmero y otros (Coord.), Psicología de la motivación y la emoción, pp. 423-452. Madrid: McGraw-Hill/Interamericana de España. 
10. Hebb, D. O. (1968). Psicología. México: Interamericana.

11. James, W. (1890/1994). Principios de psicología. México: FCE.

12. Kandel, E. R. y otros (2001). Principios de neurociencia. Madrid: McGraw-Hill. Interamericana de España.

13. Lassen, N. y otros (1980). Función cerebral y flujo sanguíneo. En El cerebro. Libros de Investigación y Ciencia, pp. 194-204. Barcelona: Labor.

14. Lazarus, R. y B. Lazarus (2000). Pasión y razón. Barcelona: Paidós Ibérica.

15. LeDoux, J. (1999). El cerebro emocional. Buenos Aires: Planeta.

16. Luria, A. R. (1977). Las funciones corticales superiores del hombre. La Habana: Orbe.

17. Mountcastle, V. (1974). Fisiología médica, vol. I. México: The C. V. Mosby Company.

18. Nauta, W. y M. Feirtag (1980). Organización del cerebro. En El cerebro, Libros de Investigación y Ciencia, pp. 53-66. Barcelona: Labor.

19. Ortega, J. (1999). Estrés y trabajo. En: http://www.medspain.com/n3_feb99/stress.htm.

20. Petri, H. L. y J. M. Govern (2006). Motivación. Teoría, investigación y aplicaciones. México: Thomson.

21. Piaget, J. (1973). Seis estudios de psicología. Barcelona: Seix Barral.

22. Pinel, J. (2001). Biopsicología. Madrid: Pearson Educación.

23. Reeve, J. (2003). Motivación y emoción. México: McGraw-Hill/Interamericana.

24. Troch, A. (1982). El stress y la personalidad. Barcelona: Herder.

25. Wittgenstein, L. (1953-1988). Investigaciones filosóficas. Barcelona: Crítica. 